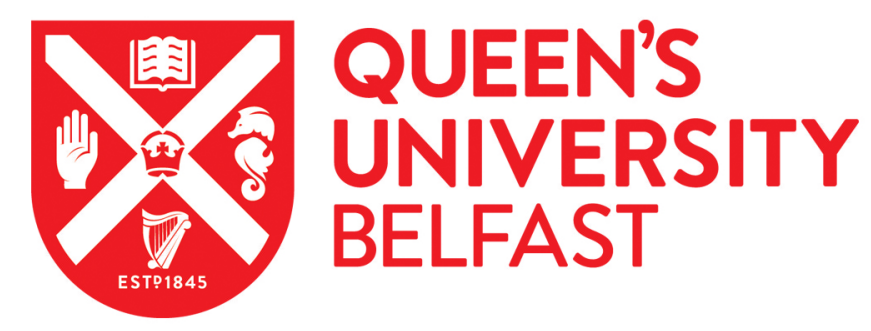

\title{
Power vs. persuasion: Can open body postures embody openness to persuasion?
}

Latu, I. M., Duffy, S., Pardal, V., \& Alger, M. (2017). Power vs. persuasion: Can open body postures embody openness to persuasion? Comprehensive Results in Social Psychology, 2(1), 68-80.

https://doi.org/10.1080/23743603.2017.1327178

\section{Published in:}

Comprehensive Results in Social Psychology

\section{Document Version:}

Peer reviewed version

Queen's University Belfast - Research Portal:

Link to publication record in Queen's University Belfast Research Portal

Publisher rights

(C) 2017 Taylor \& Francis. This work is made available online in accordance with the publisher's policies. Please refer to any applicable terms of use of the publisher.

\section{General rights}

Copyright for the publications made accessible via the Queen's University Belfast Research Portal is retained by the author(s) and / or other copyright owners and it is a condition of accessing these publications that users recognise and abide by the legal requirements associated with these rights.

Take down policy

The Research Portal is Queen's institutional repository that provides access to Queen's research output. Every effort has been made to ensure that content in the Research Portal does not infringe any person's rights, or applicable UK laws. If you discover content in the Research Portal that you believe breaches copyright or violates any law, please contact openaccess@qub.ac.uk. 
Power vs. persuasion: Can open body postures embody openness to persuasion?

Ioana M. Latu1, Sean Duffy², Vaani Pardal ${ }^{2}$, \& Madeliene Alger ${ }^{2}$

School of Psychology, Queen's University Belfast, UK

Department of Psychology, Rutgers University, Camden, USA

* Corresponding author:

Ioana Latu

i.latu@qub.ac.uk

\section{Funding}

This work was supported by a pre-registered research grant from the European Association of Social Psychology 


\begin{abstract}
In the current study we sought to replicate the finding that adopting an open/expansive body posture increases subjective feelings of power (Carney, Cuddy, \& Yap, 2010), while also investigating how these body postures influence the processing of persuasive messages. Two hundred participants were randomly assigned to adopt either an open or a closed body posture while reading either a strong or a weak persuasive message regarding junk food taxation. Afterwards, we measured participants' attitudes towards junk food, subjective feelings of power, thought confidence, and openness. Results failed to replicate the previously found effect of body posture on subjective feelings of power. Compared to weak messages, strong messages led to more persuasion, higher subjective power, more thought confidence, and more openness. However, body posture did not affect these outcomes. Overall, these findings suggest that power posture effects on are not maintained under certain conditions (e.g., a situation in which the person is not in a power role), thus challenging the idea of a direct, causal relationship between open postures and power.
\end{abstract}




\section{Power vs. persuasion: Can open body postures embody openness to persuasion?}

Arms up in the air, head tilted back, palms open. Recent research has identified this body posture as a "power posture" - a posture not only indicating but also inducing powerful feelings (Carney, Cuddy, \& Yap, 2010). But the same posture can be observed among attendees of an evangelical church or a motivational speech, where it may signal and induce openness, be it to the Holy Spirit or to new ideas.

These two possible states - power and openness - may be inconsistent with each other. In fact, power induced through role-playing before receiving a persuasive message can increase confidence in one's own thoughts, make people rely more on their existing opinions, and decrease the amount of elaboration of persuasive messages (Brinol, Petty, Valle, Rucker, \& Becerra, 2007). However, we contend that, depeding on the situation, open body postures may mean something else than power. Specifically, when placed in the role of the recipeient of a persuasive message, adopting open body postures may activate a different meaning of openness

- that of openness to persuasion. This activation would determine individuals to show opposite effects: be more open to others' messages and, as a result, increase elaboration of persuasive arguments. In sum, in the current study we investigate whether, under certain conditions, open body postures may embody openness to other's ideas rather than power.

\section{Embodied power}

Open body postures can lead people to feel more powerful subjectively (Carney et al., 2010; Park, Streamer, Huang, \& Galinsky, 2013; Ranehill et al., 2015). This increase in subjective feelings of power was accompanied by other power-related outcomes such as increased accessibility of power-related words (Huang, Galinsky, Gruenfeld, \& Guillory, 2011; Park et al., 2013), increased risk taking (Carney et al., 2010), and enhanced performance during a self- 
presentation task (Cuddy, Wilmuth, Yap, \& Carney, 2015). However, the evidence for the effect of power postures is mixed (for example, using a high powered sample, Ranehill et al. did not replicate the Carney et al. effects on risk taking) and many of the existing studies are underpowered.

Besides methodological concerns such as sample size, in the current study we also seek to address the issue of the casual process proposed in the literature on "power postures." So far, the relationship between open body postures and increased power feelings is seen as a direct, causal relationship, as emphasized by Adam and Galinsky (2012) who suggest that the symbolic meaning of the body posture is automatically embodied because it is a direct result of the physical experience. Similarly, Cuddy and colleagues cite William James's (1950) theories of emotion and ideomotor action, according to which a physiological reaction causes the experience of a certain emotion. In the same vein, it is believed that open body postures cause feelings of power through a direct link. This assumption has become so ingrained in the current discourse on body postures, that open body postures are now known and equated with power postures.

However, we have greatly advanced in the understanding of emotion since James. For example, the two factor theory of emotion suggested that the same physiological arousal can ultimately cause different emotions. One classic example comes from Schachter and Singer (1962), in which the same epinephrine injection caused participants to feel angry in one condition and euphoric in another condition, depending on the emotional state of the confederate. Although Schachter's theory was criticized and modified over the years (Cotton, 1981; LeDoux, 1995), the important idea is that later data challenged James' idea of a direct, causal relationship between physical experiences and distinct emotions. Similarly, we must 
contend be that open body postures can ultimately induce other psychological states than those related to power.

Relatedly, recent research on open body postures has shown that the effect of expansive postures on power feelings can be moderated by contextual factors. For example, in Brinol, Petty, and Wagner (2009), the direction of thoughts moderated the effects of open postures on attitudes toward the self, such that open postures led to more positive thoughts about the self only when participants wrote about their best qualities and not about their weaknesses.

In another study, open body postures led to more risk taking compared to closed body postures only when the context was social (there were faces presented), and the effect disappeared in a nonsocial context (no faces), suggesting that the effects of open body postures are moderated by action possibilities (Cesario \& McDonald, 2013). Moreover, when participants imagined being in a submissive role (e.g., being frisked by the police) while maintaining an open body posture, they behaved in a disempowered way (Cesario \& McDonald, 2013).

Overall, research suggests that, depending on contextual factors, the effect of expansive body postures on power-related feelings can be weaker, stronger, or even reversed. However, although there is evidence that the meaning of the body posture can be interpreted as lower power, there are no studies to our knowledge that investigated non-power related interpretations of open body postures. In other words, what are other psychological states that may be associated with open body postures? In the current study we investigate whether one of those outcomes is openness to persuasion, given contextual cues that do not prime power, but rather the state of being open to other people's arguments.

\section{Embodied persuasion}


There are numerous studies that show that persuasion can be embodied, such that certain positions or movements of the face or body can increase the likelihood to change one's attitude in response to a persuasive message. For example, people were more persuaded when they received persuasive messages while reclining comfortably rather than standing (Petty, Wells, Heesacker, Brock, \& Cacioppo, 1983), when nodding rather than shaking their head (Brinol \& Petty, 2003), or when they had their arm extended rather than flexed (Cacioppo, Priester, \& Berntson, 1993).

According to Brinol and Petty (2008), body states and postures influence persuasion either through evaluative conditioning (e.g., head nodding is associated with a positive reaction which, in turn, becomes associated with the persuasive message) or through increasing or reducing cognitive resources (e.g., standing takes more resources than sitting comfortably, which cognitively loads participants exposed to persuasive messages). However, although there is evidence that persuasion can be embodied, it seems imperative to revisit the issue of embodied persuasion in the light of the "power poses" literature, which equals open body postures with power without further investigating other states. Indeed, none of the existing embodied persuasion studies investigated open vs. closed body postures and whether they would embody openness to persuasion.

\section{Open body postures: Power and/or persuasion?}

In the current study we propose that the context or the implicit role cues in which the person adopts an open body posture may influence what is being embodied. If the person is asked to give a persuasive speech, make risky decisions, or imagine being a business owner who has to make decisions, such implicit task cues may activate power because participants are put in a situation in which they can influence outcomes or other people. However, if the person is placed 
in a situation in which they are exposed to persuasive messages, such implicit task cues may activate openness to persuasion. The meaning of the body posture may be interpreted differently, depending on the situation: open $=$ power when the person is in a situation in which they have to take risks (Carney et al., 2010; Huang et al., 2011), persuade others (Cuddy et al., 2015) or roleplay a business owner (Fisher et al., 2011), but open = openness to new ideas when the person is in a situation in which they are exposed to a persuasive message. In the latter case, consistent with principles of evaluative conditioning, the openness cue from the body would become associated with the message and translate into more openness to new ideas. Being open to new ideas would determine people to engage in careful, effortful processing when evaluating persuasive messages, and as such change their attitude when the persuasive message is strong, but not when the message is weak. Given that the open body postures would activate the "openness to new ideas" meaning and not the "power" meaning, we would expect these postures not to lead to increased powerful feelings and confidence in one's thoughts, a finding inconsistent with the current view on power postures (Carney et al, Cuddy).

Conversely, if there were an exclusive causal relationship between open body postures and power as proposed by the power posing literature, then we would expect open postures to lead to more powerful subjective feelings. In turn, feeling powerful would lead to having more confidence in one's own thoughts, and in terms of persuasion we should see effects similar to Studies 2 and 5 in Brinol and colleagues (2007), whereby power reduced persuasion to strong arguments because power validates a person's own initial beliefs.

It should be noted that Fischer and colleagues (2011) suggested that power postures (e.g., making a fist, open body postures) could increase confirmatory information processing, such that individuals favored information that was consistent with their point of view. This finding may 
seem inconsistent with our proposal that open body postures may increase openness to new ideas. However, we contend that the confirmatory information processing was obtained because participants were, at the same time, asked to take the role of a high power person (owner of a business who has to make decisions), thus offering contextual cues which activate the concept of power rather than openness. As such, we believe the confirmatory information processing was a result of a power manipulation, which included posture but also high power role-playing. Still, to minimize this concern, we will initially ensure that participants have a fairly neutral attitude regarding the topic of interest.

\section{The current study and hypotheses}

In the current study we seek to investigate whether open body postures can embody openness to persuasion under certain conditions. We will initially neutralize participants' attitude towards introducing a junk food tax, by asking participants to generate an equal number of arguments supporting and opposing junk food taxation and then measure their attitude towards it, which we expect to be relatively neutral. Afterwards, we will ask participants to adopt either an open or a closed body posture, using the same postures, instructions, and cover story as Carney and colleagues (2010). While adopting these postures, participants will be exposed to a persuasive message favoring the introduction of a tax on junk food. In order to enhance the extent to which these findings seek a closer replication of Carney and colleagues, we will present human faces along with the persuasive messages. We will additionally manipulate the quality of the argument, by presenting either strong or weak persuasive messages. We take this approach in order to investigate the extent to which body posture may lead to persuasion through a thoughtful, elaborate processing of the message (in which case persuasion would be enhanced by strong messages) or through a simple thoughtless process (in which case persuasion would be enhanced 
by weak messages). We will then assess participants' attitude change in line with the persuasive message, their subjective power, their openness and confidence in their own thoughts.

We propose two competing hypotheses. If open body postures exclusively embody power, then we should see effects similar to the power effects on persuasion found in Brinol et al (2007, Study 2 and 5), such that closed body posture (low power) would lead to more favorable attitudes towards junk food taxation, especially when the message contains strong arguments. Open body postures would lead to less favorable attitudes, regardless of the quality of the argument. This result would be expected because power would increase confidence in one's own thoughts, so the quality of the argument should not matter. As such, we also propose that open body postures would increase confidence in one's own thoughts and would decrease openness. Importantly, consistent with Carney and colleagues, we would also expect that open body postures increase feelings of subjective power.

Conversely, if power embodies openness to persuasion, we should see a different pattern. First, if openness of body signals openness to new ideas, we should see that participants are more deeply processing messages in open vs. closed postures and they would be, as such, especially influenced by a strong message. So we predict that participants would be most persuaded when being exposed to a strong message while holding an open posture. If the mechanism is indeed increased openness to ideas, we should also see that participants holding open body postures report being more open compared to those holding closed body postures. Inconsistent with Carney and colleagues (2010) and the literature on power and persuasion (Brinol et al., 2007; Fischer et al., 2011), open body postures should not lead to an increase in subjective power feelings and confidence in own thoughts. 
This research is important, as it will establish whether there is an exclusive, causal relationship between open body postures and powerful feelings, or whether the meaning of open body postures can be interpreted differently depending on the implicit role cues present in the situation.

\section{Method}

\section{Participants and design}

Two hundred participants (111 female, mean age 22.43 years old) were recruited on the Rutgers University-Camden campus and were paid $\$ 10$ for their participation. Participants were only excluded if they had severe difficulties in speaking, reading, or understanding English. Participants were randomly assigned to one of four conditions in a 2 (Body posture: open or closed) x 2 (Persuasive message: strong vs. weak argument) between-participants design.

The sample size was determined based on a power analysis conducted with G*Power software (Faul, Erdfelder, Lang, \& Buchner, 2007), using the Wilcox-Mann-Whitney test with an alpha level of .05. The estimated effect size used in the analysis was .50 and was obtained by averaging four effect sizes: $d=.91$ (Carney et al., 2010), $d=.48$, and $d=.28$ (Huang et al., 2011), and $d=.34$ (Ranehill et al., 2015). We used the effect sizes on subjective power feelings, as this is the main finding we are attempting to replicate. The a priori power $(1-\beta)$ was set to .95 . The resulting total $\mathrm{N}$ was 184 , which we rounded up to 200 .

\section{Procedure}

Participants were run by one of two female experimenters who were blind to the hypotheses of the study. After signing informed consent, participants were informed that the study investigated how people evaluate certain messages related to current societal issues. To begin with, participants underwent a "neutralization" procedure - we asked them to generate three arguments 
supporting and three arguments opposing the junk food taxation, in order to ensure that participants have a relatively neutral attitude towards junk food taxation at the beginning of the experiment. Using a MediaLab program, we first displayed a brief explanation of junk food taxation ("Junk food is food that has low nutritional value, typically high in sugar and produced in the form of packaged snacks needing little or no preparation. Junk food taxation would involve adding an extra tax on the sale of junk foods") and then prompted participants to alternate between generating arguments supporting and opposing junk food taxation. To check for the success of our "neutralization" strategy (or to be able to control for participants' initial opinion in further analyses if the neutralization was not successful), we then measured participants' pre-attitude towards junk food taxation.

Afterwards, participants were asked to adopt either an open or a closed body posture depending on the condition. While maintaining the assigned body posture, participants were exposed to either a strong or a weak message supporting junk food taxation, depending on the randomly assigned condition. We then measured participants' feelings of power, attitude towards junk food taxation, subjective power feelings, openness, and thought confidence. Finally, participants were debriefed. We also asked them whether they were familiar with the power posture literature (from classes or the Amy Cuddy Ted Talk).

\section{Cover story}

Participants were told " you will participate in a study which investigates how people evaluate certain messages related to global issues. Before you begin, we would like to pretest some ideas for a future study we will be conducting. For this, we are asking your help in generating arguments for and against the introduction of a tax on junk food." After generating the arguments and measuring their pre-attitude towards junk food taxation, we told participants "You 
are now ready to participate in the main study in which we will ask you to evaluate one message related to the issue of junk food taxation. Your task is to read this message and later evaluate it. As side project we are currently conducting in our lab, we are also testing the accuracy of physiological responses as a function of sensor placement. Because of this, we are asking you to hold a certain physical position."

\section{Body posture manipulation}

We used the two standing positions from Carney and colleagues (2010). Open body posture included arms away from body, palms open, feet apart, whereas the closed body posture included arms crossed across the chest, palms against the body, feet crossed at the ankles. We did not use the forward lean in the Carney and colleagues standing open position, because it may introduce a confound. More specifically, we aimed for the body posture openness to be the only factor being manipulated across the open and closed postures (e.g., participants in the open body posture condition should not be physically closer to the screen displaying the persuasive message, compared to those in the closed body posture condition). Pictures similar to Carney and colleagues were used as models. A screen displaying the persuasive message was placed at eye level in front of the participants. We also presented faces along with the persuasive message. Persuasive messages

Both the strong and weak messages are included in Appendix 1.

\section{Measures}

Pre-attitude about junk food taxation. Following the neutralization procedure and before being exposed to the persuasive message, participants were asked to rate junk food taxation on three 9point (1-9) semantic differential scales (against - in favor, unfavorable-favorable, bad-good). The items were averaged to create a composite pre-attitude index $(M=5.23, S D=2.07$, 
Cronbach's $\alpha=.92$ ), with higher numbers denoting more positive attitudes towards junk food taxation.

Post-attitude about junk food taxation. Following the persuasive message, participants were asked to rate junk food taxation on three 9-point (1-9) semantic differential scales (against-in favor, unfavorable - favorable, bad-good). The items were averaged to create a composite postattitude index $(M=6.08, S D=2.14$, Cronbach's $\alpha=.93)$, with higher numbers denoting more positive attitudes towards junk food taxation.

Sense of power. Consistent with Carney et al. (2010) and Ranehill et al. (2015), participants indicated how "powerful" and "in charge" they felt on a scale from 1 (not at all) to 4 (a lot). The items were averaged to create a composite subjective power index $(M=2.51, S D=0.89$, Cronbach's $\alpha=.83$ ), with higher numbers denoting higher sense of power.

Thought direction and confidence. We asked participants to list the thoughts that went through their mind when exposed to the message about junk food taxation. After listing their thoughts, we asked participants to rate on 9-point scales how favorable the thought was $(1=$ not at all favorable, $9=$ extremely favorable $)$, how confident they were in that thought $(1=$ not at all confident, $9=$ extremely confident $)$, and how valid they believed the thought to be $(1=$ not at all valid, $9=$ extremely valid). The last two items were averaged to create a composite thought confidence index $(M=7.71, S D=1.23$, Cronbach's $\alpha=.94)$, with higher numbers denoting more confidence in own thoughts.

Openness. Participants rated four statements on a scale from 1 (Strongly Disagree) to 9 (Strongly Agree), as they relate to their state while reading the persuasive message. The items are "Ifeel open to new ideas" "I welcome thinking about new ideas" "I like to entertain different points of view" and "I am curious about many different things." The items were averaged to create a 
composite openness index $(M=6.42, S D=1.56$, Cronbach's $\alpha=.85)$, with higher numbers denoting more openness.

\section{Results}

\section{Preliminary analyses}

As a preliminary analysis, we investigated whether the pre-attitude towards junk food taxation was indeed neutral, by computing a one-sample t-test against the value of 5 - the midpoint of the scale. The mean attitude towards junk food taxation before the experimental manipulation was $M$ $=5.23, S D=2.07$, which was not significantly different from $5, t(199)=1.60, p=.112$, Cohen's $d=.11,95 \%$ CI $[-0.05,0.52]$. Given the lack of significance and the small effect size, this variable was not used as a covariate in future analyses.

Persuasion. To test our main research question regarding the effects of body posture on persuasion, we conducted a 2 (Body posture: open or closed) x 2 (Persuasive message: strong vs. weak) between-participants ANOVAs on the post-attitude towards junk food taxation. Results showed a main effect of message strength, $F(1,196)=10.72, p=.001$,Cohen's $d=.46,95 \% \mathrm{CI}$ $[0.39,1.55]$, such that strong messages $(M=6.57, S D=2.24)$ led to more persuasion compared to weak messages $(M=5.60, S D=1.94)$. This result shows that our manipulation of message strength was successful and replicated previous research. The main effect of body posture on attitudes towards junk food was not significant, $F(1,196)=1.67, p=.197$, Cohen's $d=.18$, 95\% CI [-0.20, 0.97], although an inspection of the means suggested a trend for open body postures to lead to more persuasion $(M=6.27, S D=2.07)$ compared to closed body postures $(M$ $=5.89, S D=2.21)$. The interaction between posture and message strength was not significant, $F$ $(1,196)=.05, p=.83, \eta^{2}=.0001$. 
Subjective feelings of power. In order to investigate whether Carney and colleagues effects of body postures on subjective power replicate, we conducted a 2 (Body posture: open or closed) x 2 (Persuasive message: strong vs. weak) between-participants ANOVAs on subjective power. Results did not replicate Carney and colleagues' findings, such that there was no main effect of body posture on subjective power, $F(1,196)=1.19, p=.28$, Cohen's $d=.15,95 \%$ CI $[-0.10,0.36]$. In other words, participants who adopted open body postures did not feel more powerful $(M=2.57, S D=0.79)$ compared to participants who adopted closed body postures $(M$ $=2.44, S D=0.98)$. The interaction between posture and message strength was not significant either, $F(1,196)=.45, p=.50, \eta^{2}=.002$. However, further validating our message strength manipulation, there was a main effect of message strength on subjective power feelings, $F(1$, 196) $=22.81, p=.0001$, Cohen's $d=.68,95 \%$ CI [0.33, 0.80], with participants feeling more powerful after being exposed to a strong message $(M=2.79, S D=0.79)$ compared to a weak message $(M=2.22, S D=0.89)$.

Thought confidence analyses. We also conducted a 2 (Body posture: open or closed) x 2 (Persuasive message: strong vs. weak) between-participants ANOVA on the thought confidence score. There was a main effect of message strength on confidence $F(1,195)=5.68, p=.02$, Cohen's $d=.35,95 \%$ CI [0.07, 0.75], with participants feeling more confident in their thoughts regarding junk food taxation after being exposed to a strong message $(M=7.92, S D=1.06)$ compared to a weak message $(M=7.50, S D=1.35)$. However, the main effect of body posture on thought confidence was not significant $F(1,195)=0.003, p=.96$, Cohen's $d=.008,95 \% \mathrm{CI}$ $[-0.35,0.33]$, with no difference in thought confidence between participants who adopted an open body posture $(M=7.71, S D=1.31)$ compared to a closed body posture $(M=7.72, S D=$ 
1.14). The interaction between body posture and message strength was not significant either, $F$ $(1,195)=1.11, p=.29, \eta^{2}=.006$.

Openness. Finally, we conducted a 2 (Body posture: open or closed) x 2 (Persuasive message: strong vs. weak) between-participants ANOVA on the openness score. Results showed a similar pattern, with a main effect of message strength on openness, $F(1,196)=18.64, p$ $=.0001$, Cohen's $d=.61,95 \% \mathrm{CI}[0.50,1.34]$, such that participants exposed to a strong message felt significantly more open to arguments $(M=6.87, S D=1.49)$ compared to those exposed to weak messages $(M=5.96, S D=1.50)$. The main effect of posture on openness was not significant, $F(1,196)=0.58, p=.44$, Cohen's $d=.11,95 \%$ CI $[-0.58,0.26]$, with participants not differing in their openness feelings in an open $(M=6.33, S D=1.53)$ compared to a closed body posture $(M=6.50, S D=1.59)$. Furthermore, the interaction between body posture and message strength was not significant, $F(1,196)=0.23, p=.63, \eta^{2}=.001$.

\section{Discussion}

In the current study we proposed two competing hypotheses. According to the first hypothesis, open body postures would increase feelings of subjective power, thus supporting the idea of an exclusive, causal relationship between open body postures and power (Adam \& Galinsky, 2012; Carney et al., 2010). As a competing hypothesis, we proposed that open body postures might embody openness to persuasive arguments, thus supporting the idea that the implicit role cues present in the situation may change the interpretation of the body posture.

The results of the current study failed to show effects of body postures either on subjective power feelings or attitude change following a persuasive message. First, using a high powered sample size, we did not replicate the Carney et al. (2010) effects of posture on power, such that participants who adopted open body postures did not feel more powerful compared to 
those who adopted closed body postures. Second, the competing hypothesis regarding persuasion was not supported either. Although the direction of the means suggested that open body postures might lead to more positive attitudes following a persuasive message, this difference was not significant. The predicted interactions with the strength of the persuasive message were not supported either.

It should also be added that our findings did not suggest that body posture influenced cognitive processes. Across all dependent variables, we found an effect of persuasive message strength, but this main effect was not moderated by body posture. This finding suggests that all participants, regardless of their body posture, were engaging in thoughtful processing, hence being more persuaded, confident, and open when hearing a strong compared to a weak message. This finding does not support previous work (e.g., Huang et al., 2011) suggesting that open body postures influence power-related cognitions.

There are several reasons why we may not have replicated the results of Carney and colleagues (2010). First, consistent with our theoretical reasoning, we did not replicate the effects of body posture on power because the cues within the situation were not consistent with the power role - participants were being persuaded rather than persuading others (Cuddy et al., 2015) or asked to take risky decisions (Carney et al., 2010). As such, this finding challenges the idea of a direct causal relationship between body posture and power. Second, there may be several methodological differences between our study and the Carney and colleagues work. For example, faces were presented simultaneously along with the persuasion message. In terms of postures, we only used the standing open and closed postures. Moreover, the open standing posture did not include the forward lean, as we considered this to be a potential confound - it would be unclear whether effects on subjective power would be accounted for by the openness of 
the posture or the forward lean which suggests approach behavior. Indeed, increased power has been associated with approach-related tendencies (Keltner, Gruenfeld, \& Anderson, 2003).

It is also worth exploring the reasons why we did not find effects of body posture on persuasion. First, it may be that the message should be delivered through audio rather than writing, because reading a complex message and holding a certain posture for several minutes may increase physical discomfort, which may negatively affect persuasion capacity (Brinol \& Petty, 2008). Using a persuasive message presented through audio may also be advised for future research because the effects of posture on persuasion may be more likely to occur within a perceived social interaction with another person rather than by reading a written message. Future research should investigate the effects of posture on attitude change and processing in more realistic social interactions, which are more likely to activate implicit cues that influence the interpretation of the body posture.

\section{Conclusions}

Using a high-powered sample we were not able to replicate the previous findings on power postures. We did not find support for a direct, causal relationship between open body postures and subjective power, which suggests caution in interpreting the result of Carney and colleagues (2010), as well as subsequent talks and popular books. It is possible that power effects were not replicated because they only occur under specific conditions (e.g., participants being placed in an implicit power role). The current study advances our understanding of such a situation in which power posing is not successful in inducing power feelings. 


\section{References}

Adam, H., \& Galinsky, A. D. (2012). Enclothed cognition. Journal of Experimental Social Psychology, 48, 918-925. doi: http://dx.doi.org/10.1016/j.jesp.2012.02.008

Anderson, C., John, O. P., \& Keltner, D. (2012). The personal sense of power. Journal of Personality, 80, 313-344. doi: http://dx.doi.org/10.1111/j.1467-6494.2011.00734.x

Brinol, P., \& Petty, R. E. (2003). Overt head movements and persuasion: A self-validation analysis. Journal of Personality and Social Psychology, 84, 1123-1139. doi: http://dx.doi.org/10.1037/0022-3514.84.6.1123

Brinol, P., \& Petty, R. E. (2008). Embodied persuasion: Fundamental processes by which bodily responses can impact attitudes Embodied grounding: Social, cognitive, affective, and neuroscientific approaches (pp. 184-207). New York, NY: Cambridge University Press; US.

Brinol, P., Petty, R. E., Valle, C., Rucker, D. D., \& Becerra, A. (2007). The effects of message recipients' power before and after persuasion: A self-validation analysis. Journal of Personality and Social Psychology, 93, 1040-1053. doi: http://dx.doi.org/10.1037/00223514.93.6.1040

Brinol, P., Petty, R. E., \& Wagner, B. (2009). Body posture effects on self-evaluation: A selfvalidation approach. European Journal of Social Psychology, 39, 1053-1064. doi: http://dx.doi.org/10.1002/ejsp.607

Cacioppo, J. T., Priester, J. R., \& Berntson, G. G. (1993). Rudimentary determinants of attitudes: II. Arm flexion and extension have differential effects on attitudes. Journal of Personality and Social Psychology, 65, 5-17. doi: http://dx.doi.org/10.1037/0022-3514.65.1.5 
Carney, D. R., Cuddy, A. J., \& Yap, A. J. (2010). Power posing: Brief nonverbal displays affect neuroendocrine levels and risk tolerance. Psychological Science, 21, 1363-1368. doi: http://dx.doi.org/10.1177/0956797610383437

Cesario, J., \& McDonald, M. M. (2013). Bodies in context: Power poses as a computation of action possibility. Social Cognition, 31, 260-274. doi:

http://dx.doi.org/10.1521/soco.2013.31.2.260

Cotton, J. L. (1981). A review of research on Schachter's theory of emotion and the misattribution of arousal. European Journal of Social Psychology, 11, 365-397. doi: http://dx.doi.org/10.1002/ejsp.2420110403

Cuddy, A. J., Wilmuth, C. A., Yap, A. J., \& Carney, D. R. (2015). Preparatory power posing affects nonverbal presence and job interview performance. Journal of Applied Psychology, 100, 1286-1295. doi: http://dx.doi.org/10.1037/a0038543

Faul, F., Erdfelder, E., Lang, A.-G., \& Buchner, A. (2007). G*Power 3: A flexible statistical power analysis program for the social, behavioral, and biomedical sciences. Behavior Research Methods, 39(2), 175-191. doi: http://dx.doi.org/10.3758/BF03193146

Fischer, J., Fischer, P., Englich, B., Aydin, N., \& Frey, D. (2011). Empower my decisions: The effects of power gestures on confirmatory information processing. Journal of Experimental Social Psychology, 47, 1146-1154. doi: http://dx.doi.org/10.1016/j.jesp.2011.06.008

Huang, L., Galinsky, A. D., Gruenfeld, D. H., \& Guillory, L. E. (2011). Powerful postures versus powerful roles: Which is the proximate correlate of thought and behavior? Psychological Science, 22, 95-102. doi: http://dx.doi.org/10.1177/0956797610391912

James, W. (1950). The principles of psychology. 
Keltner, D., Gruenfeld, D. H., \& Anderson, C. (2003). Power, approach, and inhibition. Psychological Review, 110, 265-284. Doi: http://dx.doi.org/10.1037/0033295X.110.2.265

LeDoux, J. E. (1995). Emotion: Clues from the brain. Annual Review of Psychology, 46, 209235. doi: http://dx.doi.org/10.1146/annurev.ps.46.020195.001233

Park, L. E., Streamer, L., Huang, L., \& Galinsky, A. D. (2013). Stand tall, but don't put your feet up: Universal and culturally-specific effects of expansive postures on power. Journal of Experimental Social Psychology, 49, 965-971. doi: http://dx.doi.org/10.1016/j.jesp.2013.06.001

Petty, R. E., Wells, G. L., Heesacker, M., Brock, T. C., \& Cacioppo, J. T. (1983). The effects of recipient posture on persuasion: A cognitive response analysis. Personality and Social Psychology Bulletin, 9, 209-222. doi: http://dx.doi.org/10.1177/0146167283092004

Ranehill, E., Dreber, A., Johannesson, M., Leiberg, S., Sul, S., \& Weber, R. A. (2015). Assessing the robustness of power posing: No effect on hormones and risk tolerance in a large sample of men and women. Psychological Science, 26, 653-656. doi: http://dx.doi.org/10.1177/0956797614553946

Riskind, J. H. (1984). They stoop to conquer: Guiding and self-regulatory functions of physical posture after success and failure. Journal of Personality and Social Psychology, 47, 479493. doi: http://dx.doi.org/10.1037/0022-3514.47.3.479

Schachter, S., \& Singer, J. (1962). Cognitive, social, and physiological determinants of emotional state. Psychological Review, 69, 379-399. doi: http://dx.doi.org/10.1037/h0046234 


\section{Appendix 1}

\section{Pro-Junk Food Tax (Strong Persuasive Message)}

\section{In Favor of Junk Food Taxation}

Some states in the United States are considering legislation on the taxing of junk food. When taking many factors into consideration, this program seems likely to bring about a number of good things.

According to some proponents of this legislation, taxing junk food will provide money for many government-based initiatives. For example, they estimate that a one-cent tax per 12-ounce soft drink could generate about $\$ 1.5$ billion annually which could be spent on promoting physical activity and nutrition education. In addition, a penny tax per pound of candy would raise about $\$ 70$ million. Large amounts of money like this could be used to fund a number of healthy lifestyle programs and to subsidize health insurance for people suffering from obesity.

In addition to the economic benefits, placing a tax on junk food will encourage healthy eating. According to Stanford Professor Keith Brown, a major reason people eat junk food is because it is cheap and convenient. Dr. Brown says that so much cheap junk food creates a "toxic environment" of sweetened food. This junk food is more calorically dense than healthy food, so people are much more likely to gain weight. Taxing junk food could make people choose healthier alternatives because the junk food would no longer be cheaper in the long run. Moreover, Dr. Brown proposes to tax junk food to make unhealthy food more expensive and to use the funds from the tax to decrease the costs of healthy food by $70 \%$. By taking the pressure 
off of individuals to choose between food quality and food value, people will feel more positive towards buying and eating healthier food.

By promoting healthy eating habits, this taxation would also have an indirect impact on the nation's obesity problem (and medical conditions related to obesity). The Journal of the American Medical Association reports that in 2001, 44.3 million Americans were obese and the number of Americans with diabetes increased 61\% since 1990. A report from the Journal of Food Analysis found that Americans receive nearly one-third of their calories from junk food. These facts are even more alarming when one realizes that diseases like diabetes cost millions of dollars annually in health care and lost productivity. In a 1992 study that assessed the direct costs of treating diabetes in the U.S., the American Diabetes Association found that the estimated total expenditure for 1 year was $\$ 45.2$ billion. Because eating large amounts of junk food is associated with being obese and is related to a higher risk for costly diseases like diabetes, junk food is a major contributor to the current obesity problem.

\section{Pro-Junk Food Tax (Weak Persuasive Message)}

In Favor of Junk Food Taxation

Some states in the United States are considering legislation on the taxing of junk food. When taking many factors into consideration, this program seems likely to bring about a number of good things.

According to some proponents of this legislation, taxing junk food will provide money for some government-based initiatives. For example, they estimate that a one-cent tax per 12-ounce soft drink could generate a small amount of money annually which could be spent on a number of different things. In addition, a penny tax per pound of candy could create a small increase in 
funds as well. Amounts of money like this could be used to partially fund programs for a small number of citizens.

In addition to the economic benefits, placing a tax on junk food might encourage healthy eating. According to college student Keith Brown, a major reason people eat junk food is because it is cheap and convenient. Brown says that so much cheap junk food creates a "toxic environment" of sweetened food. This junk food is somewhat more calorically dense than healthy food, so people are more likely to gain weight. Taxing junk food could make people choose healthier alternatives because the junk food would no longer be much cheaper in the long run. Brown proposes to tax junk food in order to negatively affect junk food producers and in turn, decrease the large amount of junk food that has become too readily available for consumers. By taking the pressure off of individuals to choose between food quality and food value, people will feel more positive towards buying and eating healthier food.

By promoting healthy eating habits, this taxation may also have an indirect impact on the nation's obesity problem (and medical conditions related to obesity). Another college student reports that in 2001, 15.3 million Americans were obese and the number of Americans with joint pain increased 2\% since 1990. A report from a local newspaper found that Americans receive nearly one-twelfth of their calories from junk food. These facts are even more alarming when one realizes that conditions such as joint pain cost thousands of dollars annually in health care and lost productivity. In a 1992 survey that assessed the indirect costs of treating sufferers of joint pain, one health clinic found that the estimated total expenditure for 1 year was $\$ 100,000$. Because eating large amounts of junk food is associated with being obese and is related to a higher risk for costly medical conditions like joint pain, junk food is a major contributor to the current obesity problem. 
